\title{
Composite Magnetic Sorbents Based on Iron Oxides in Different Polymer Matrices: Comparison and Application for Removal of Strontium
}

\author{
Andrei Egorin*(D), Eduard Tokar ${ }^{\mathbb{D}}$, Anna Matskevich, Nikita Ivanov, Ivan Tkachenko, \\ Tatiana Sokolnitskaya $\mathbb{D}^{\mathbb{D}}$ and Larisa Zemskova \\ Institute of Chemistry, Far Eastern Branch, Russian Academy of Sciences, 690022 Vladivostok, Russia; \\ d.edd@mail.ru (E.T.); mysmatskevich@mail.ru (A.M.); ivanov.np@students.dvfu.ru (N.I.); \\ tkachenko@ich.dvo.ru (I.T.); sokolnitskaya@ich.dvo.ru (T.S.); zemskova@ich.dvo.ru (L.Z.) \\ * Correspondence: andrey.egorin@gmail.com; Tel.: +7-423-2311-889
}

Received: 31 March 2020; Accepted: 15 May 2020; Published: 18 May 2020

\begin{abstract}
Introduction of magnetic nanoparticles into composite sorbents based on polymer matrices has received great attention due to the possibility of using cheap iron oxides and removing spent sorbents by means of magnetic separation. In the present paper, we discuss the problem of creating magnetic sorbents using two types of matrices as host materials: synthetic cation exchange resin and natural aminopolysaccharide chitosan. The possibilities of applying matrices for the in situ formation of oxide phases of a specified composition with the required content of an inorganic component in a composite material were estimated. The composition of the oxide phase formed in the composite material was studied, and particle sizes were evaluated by the method of X-ray diffraction analysis. Magnetic characteristics were investigated. Sorption characteristics with respect to strontium for the composites containing iron oxides were determined.
\end{abstract}

Keywords: magnetic chitosan composites; polymeric sorbents and biosorbents; iron oxides; strontium; adsorption

\section{Introduction}

To solve many problems of environmental protection, sorption methods employing various sorbents are used extensively; the popular sorbents, aside from carbon materials and ion-exchange resins, include those based on natural biopolymers, for example, cellulose and its modifications [1-6] or chitosan [7-14].

In recent years, numerous nanosized metal oxides/hydroxides, such as those of iron, aluminum, manganese, titanium, magnesium, cerium, etc., have received ever-increasing attention of researchers as adsorbents $[15,16]$. They can be used as catalytic materials, coloring agents, gas sensors, magnetic resonance imaging, and drug delivery agents. The most promising of these metal oxides in the function of adsorbents are iron oxides and composites based on them, which can be used for the removal of heavy metals, radionuclides, and arsenic, as well as for the isolation and concentration of organic compounds [17-19]. Iron oxides are cheap, non-toxic, and have a wide range of applications, but their main advantage consists in the fact that they can be removed from the solutions to be decontaminated by magnetic separation $[17,20]$.

Numerous researchers reported that there were a number of problems to be solved in order to apply nanopowders directly in decontamination systems. First, oxide nanopowders are normally unstable and tend to agglomerate. Second, recycling powders from treated waters (except for magnetic nanomaterials) is practically impossible due to their incomplete separation and contamination of the treated solutions with nanoparticles, the toxicity of which has not been exhaustively determined [15-17,20]. 
To overcome these technical difficulties, iron oxide nanopowders were introduced to conventional porous adsorbents, including activated carbon, cellulose and alginate granules, and synthetic resins $[16,19,21]$. Both cation- and anion-exchange materials can be used as synthetic resins [21]. The application of a macroporous polystyrene anion exchanger, D-201, was reported earlier [22]. The authors of [23] investigated magnetic materials based on microporous and biporous hypercrosslinked polystyrenes and a mesoporous sorbent, XAD-4. The authors of [24] compared the sorption properties with respect to arsenic for two hybrid sorbents; the first one contained hydrous iron oxides and was fabricated on the basis of a strongly basic gel-type anion exchanger, a resin with quaternary amine functional groups, and an Arsen $X^{n p}$ sorbent. The commercial sorbent Arsen $X^{n p}$ is a hybrid sorbent in which nanosized iron oxide particles are introduced into a strong-base anion exchanger based on a polystyrene matrix with quaternary amino groups $[21,25]$.

However, ion-exchange resins are characterized by high cost, and their synthesis technologies are rather complicated; furthermore, the raw materials for their production are not renewable. Natural biopolymers can serve as alternatives to ion-exchange resins; the comparison characteristics of synthetic polymer matrices and biopolymers were provided in [16]. The former ones were characterized by a cross-linked structure suitable for stable immobilization, excellent mechanical properties, chemical stability and compatibility, regulated structure, a charged surface that promotes the dispersion of the modifier and pollutant nanoparticles, and easiness of separation from solutions. On the other hand, biopolymers are readily available and widely spread, are built from moderately flexible chiral molecules, are hydrophilic, and are environmentally safe.

Chitosan is the most favorable among the biopolymers for the immobilization of inorganic components or "guests", which was stated in reviews [16-21,26] and articles [27-30]. A natural polysaccharide chitosan is a product of deacetylation of chitin and characterized with a unique combination of properties, such as biodegradability, bioactivity, biocompatibility and non-toxicity, and low ash content. However, it has also significant disadvantages, including low stability in acidic media, unsatisfactory mechanical properties, low thermal stability, resistance to mass transfer, and low porosity and surface area. These disadvantages can be overcome by preparing chitosan composites or by modifying chitosan using physical or chemical methods. Physical modification is performed by converting the chitosan powder into a gel (granules, membranes, films, etc.) or nanoparticles. This can result in the increase of the porosity, surface area, and number of adsorption sites, the reduction of crystallinity, and the increase of swelling and diffusion characteristics. Chemical modification can increase the stability and reduce the solubility in an acidic medium. It includes cross-linking of polymer units, grafting selective groups on the polymer chain, and impregnation.

The functionalized polymer phase mainly serves as a host, while inorganic particles of the metal oxide phase are finely dispersed in the host material. Synthesis of such hybrid materials can be carried out in two ways: (1) by dispersing ready-made iron oxide nanoparticles in a preliminarily obtained or commercial polymer; (2) and directly through the process of preparation (or deposition) of the polymer $[20,21]$.

Iron oxides are adsorbents for various classes of contaminants; however, using such inorganic ion exchangers for the removal of radionuclides is of urgent interest. In the present work, we describe the results of strontium removal by two types of hybrid sorbents based on iron oxides immobilized into different inorganic matrices (ion-exchange resin and chitosan). The works on the application of iron oxides for removal of the Sr-90 isotope are not numerous and describe as natural oxide minerals as synthetic oxides of various compositions embedded into a chitosan matrix. Besides, it is important to determine what type is necessary to select for synthesis of an active component in it, namely, iron oxide, since the biopolymer, unlike the ion-exchange resin, is known to be incapable of adsorbing strontium.

Strontium represents one of the relevant contaminants in terms of radioecological safety. As was reported earlier, iron oxide minerals [31] and synthetic iron oxides of various compositions immobilized in a chitosan matrix [30,32-34] were used for the removal of strontium. 
It appears urgent to compare the capabilities of composite materials in which the active component (iron oxide) is immobilized in a polymer matrix during its production in situ. The objective of the present work was to prepare magnetic sorbents based on a strong KU-2 cation exchanger (styrene and divinylbenzene copolymer) and a natural polysaccharide chitosan to study the composition of the formed iron oxide phases, evaluate the size of particles formed in polymer matrices, and determine and compare the magnetic characteristics and sorption properties of the resulting composites with respect to strontium.

\section{Results}

\subsection{Sorbents Characteristics}

Figure 1 shows the SEM-images of the surface of the 3M, 3M-2, and 3M-4 sorbents (Figure 1a-c) and the cross-section of the KU-MAG sorbent granule (Figure 1d). The surface of the 3M sorbent is monolithic, with inclusions of flakes and particles formed, probably, in the process of the material grinding. The iron distribution over the surface is relatively homogeneous. The surface of the $3 \mathrm{M}-2$ is looser while the iron distribution is also relatively homogeneous. The morphology of the 3M-4 sorbent is heterogeneous, has a sponge-like structure, and contains areas different in color. According to the element distribution map, light areas are, probably, represented by an iron oxide phase, whereas dark areas correspond to chitosan. The cross-section of a KU-MAG particle is even, the upper layer, with a thickness of 70-80 $\mu \mathrm{m}$, is lighter and is represented by an iron oxide phase in accordance with the element distribution map.
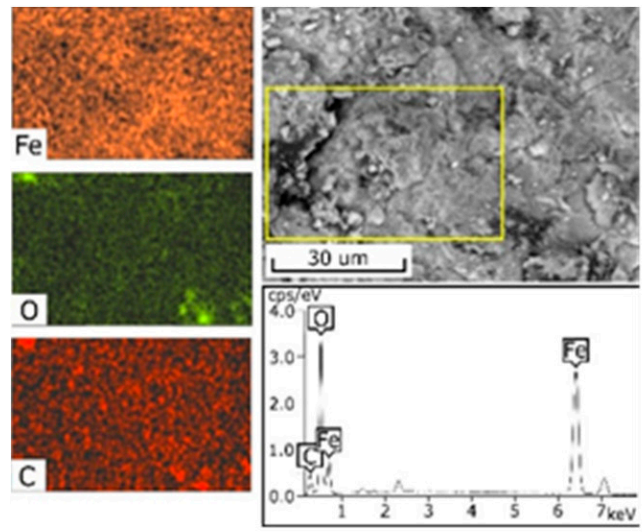

(a)

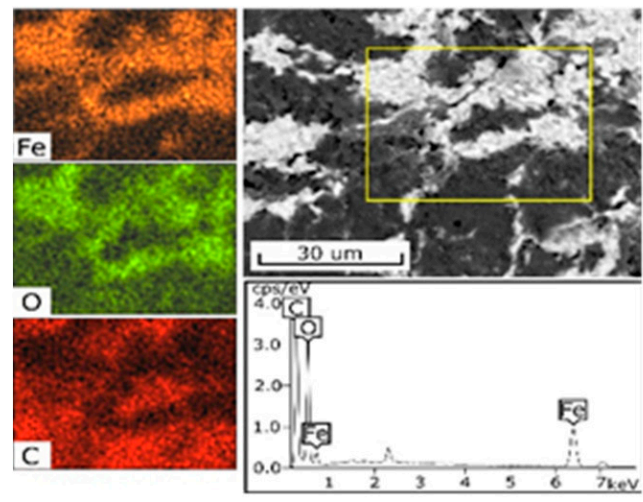

(c)
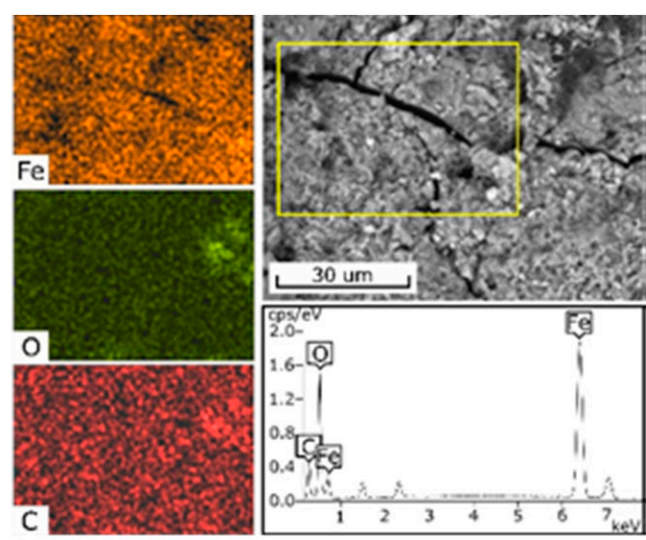

(b)
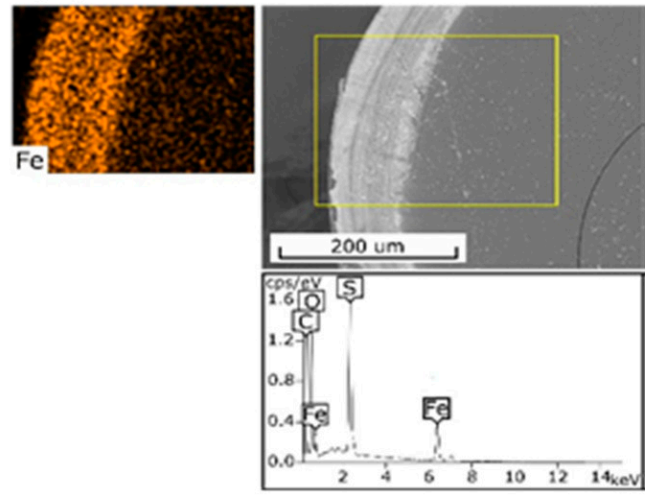

(d)

Figure 1. SEM-EDX analysis of composite sorbents, the yellow rectangle is the analysis area: (a) 3M, (b) 3M-2, (c) 3M-4, (d) KU-MAG. Scale bar (a-c) $30 \mu \mathrm{m}$, (d) $200 \mu \mathrm{m}$. 
The results of the X-ray diffraction analysis of the magnetic sorbents in polymer matrices are shown in Figures 2 and 3. $\mathrm{Fe}_{3} \mathrm{O}_{4}$ magnetite (00-900-2674) and $\mathrm{FeO}(\mathrm{OH})$ goethite (00-901-0406) were identified in the chitosan matrix using the Crystallography Open Database (COD) [35]. Moreover, the MAG sample data were characterized by the presence of peaks attributed to the phase of silicon carbide (00-101-1053), likely related to impurities in the initial chitosan.

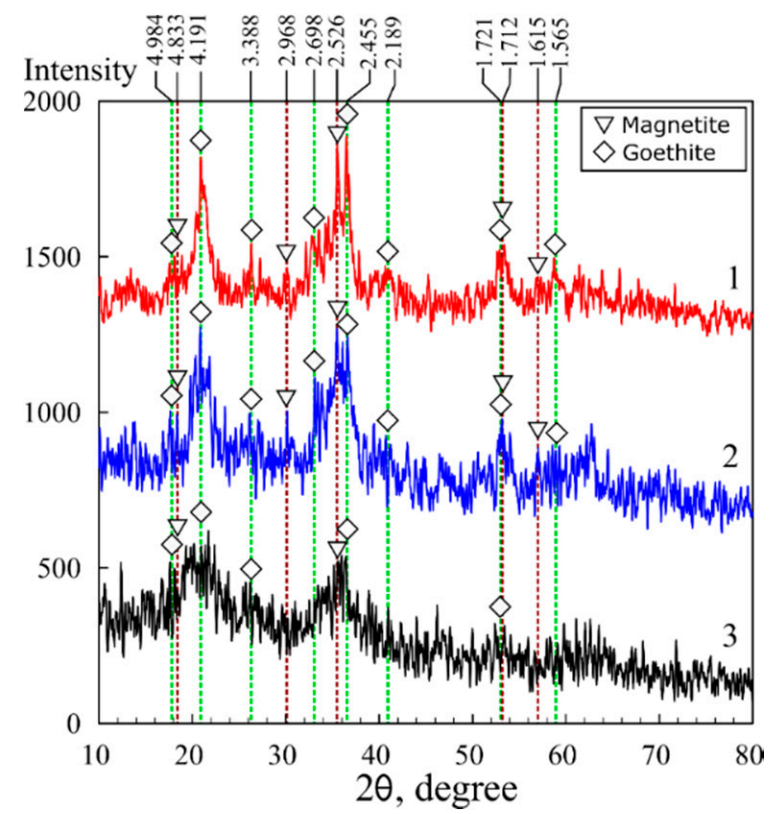

Figure 2. X-ray diffraction patterns of the magnetic composites based on chitosan: 1—sorbent 3M, 2-sorbent 3M-2, 3-sorbent 3M-4.

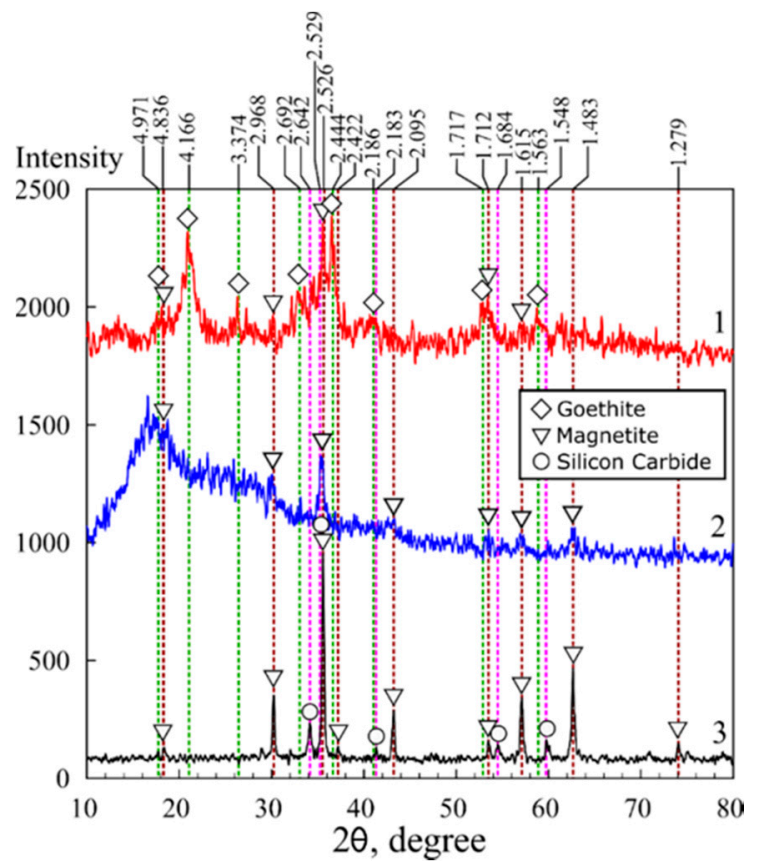

Figure 3. X-ray diffraction patterns: 1—sorbent 3M, 2-sorbent KU-MAG, 3-sorbent MAG.

Crystalline sizes estimated on the basis of the XRD data of the prepared composites for different $2 \theta$ are presented in Table 1.

Table 2 shows the results of estimation of the stability of composite sorbents in an $\mathrm{NaCl}$ solution of a concentration of $0.1 \mathrm{~mol} / \mathrm{L}$. In accordance with the presented data, one can conclude that composite 
sorbents are distinguished with high mechanical stability and do not tend to destruct with prolonged contact with the solution to be decontaminated.

Table 1. Particle sizes of iron oxides in the investigated sorption materials.

\begin{tabular}{|c|c|c|c|c|c|c|c|c|c|c|c|}
\hline \multirow{2}{*}{ Samples } & \multicolumn{11}{|c|}{ Sizes $(\mathrm{nm})$ for $2 \theta$ Angles } \\
\hline & 20.3 & 20.9 & 21.5 & 30.2 & 30.3 & 34.5 & 35.5 & 35.6 & 35.3 & 35.6 & 35.9 \\
\hline $\mathrm{M}$ & & 9.7 & & & & & 7.9 & & & & \\
\hline $3 \mathrm{M}-2$ & & 5.9 & & & & & 6.4 & & & & \\
\hline $3 \mathrm{M}-4$ & & 12 & & & & & 5.2 & & & & \\
\hline MAG & & & & & 27.8 & & & & & & \\
\hline KU-MAG & & & & & & & & & & & \\
\hline
\end{tabular}

Table 2. Results of estimation of the stability of composite sorbents in $\mathrm{NaCl}$ solution $(0.1 \mathrm{~mol} / \mathrm{L})$.

\begin{tabular}{ccc}
\hline Sorbent & Washed-Out Iron Mass $(\mathbf{m g}){ }^{*}$ & Washed-Out Iron Fraction $(\%)$ \\
\hline $3 \mathrm{M}$ & 0.1 & 0.02 \\
\hline $3 \mathrm{M}-2$ & 0.08 & 0.04 \\
\hline 3M-4 & 0.18 & 0.17 \\
\hline KU-MAG & 0.12 & 0.23 \\
\hline
\end{tabular}

${ }^{*}$ Recalculated to composite mass; ** Recalculated to mass fraction of inorganic phase.

\subsection{Magnetic Properties}

Figure 4 shows field dependences of the magnetization of the composites with different contents of iron oxide (obtained at room temperature).

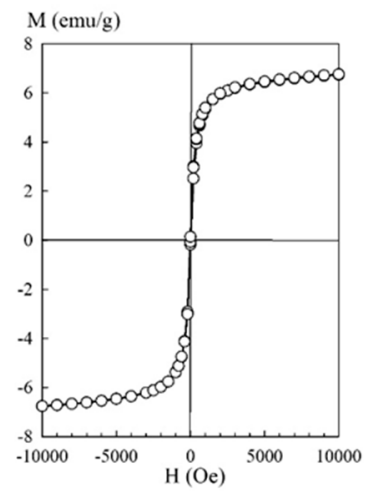

(a)

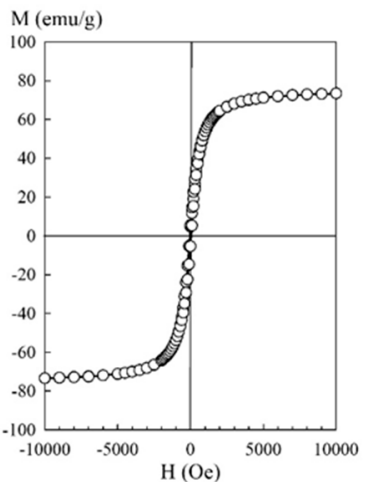

(d)

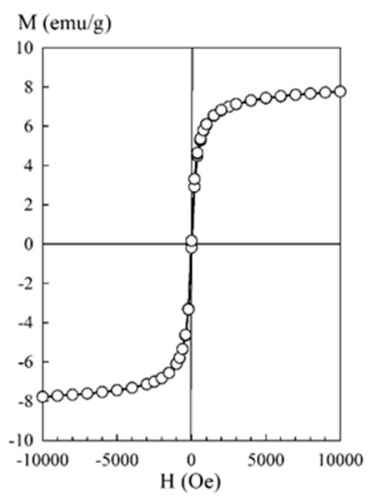

(b)

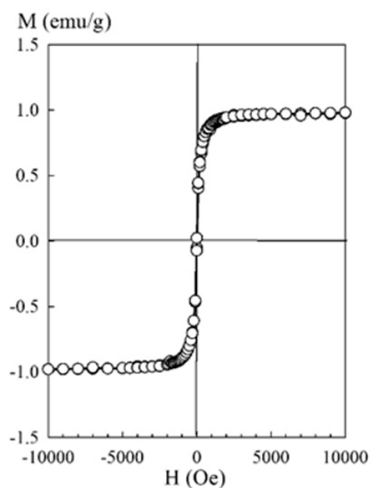

(e)

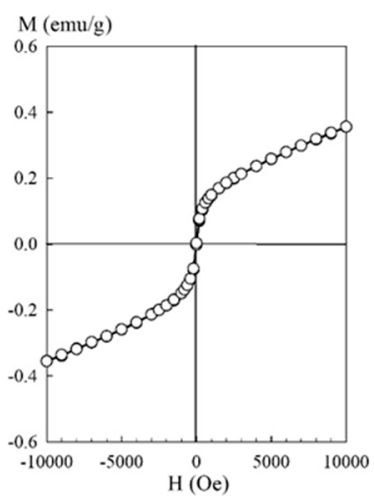

(c)

Figure 4. Dependence of the magnetization $\mathrm{M}(\mathrm{emu} / \mathrm{g})$ on the magnetic field $\mathrm{H}(\mathrm{Oe})$ : (a) sorbent $3 \mathrm{M}$, (b) sorbent 3M-2, (c) sorbent 3M-4, (d) sorbent MAG, (e) sorbent KU-MAG. 


\subsection{Sorption Properties}

Figure 5 shows isotherms of strontium sorption from a neutral $\mathrm{NaCl}$ solution of a concentration of $0.1 \mathrm{~mol} / \mathrm{L}$ and nonlinear regression curves obtained using respective equations. The obtained sorption isotherm according to Giles classification could be attributed to the L-type or H-type, which indicated high affinity of the composite materials with respect to $\mathrm{Sr}^{2+}$ ions in the region of low concentrations.

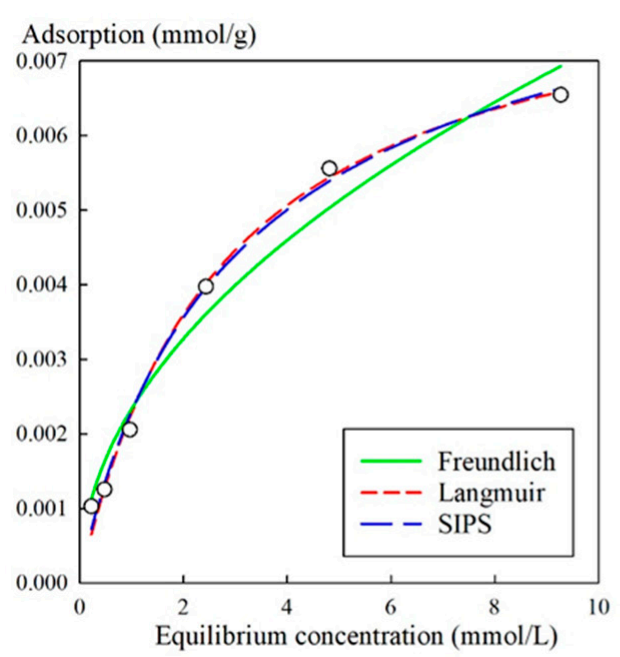

(a)

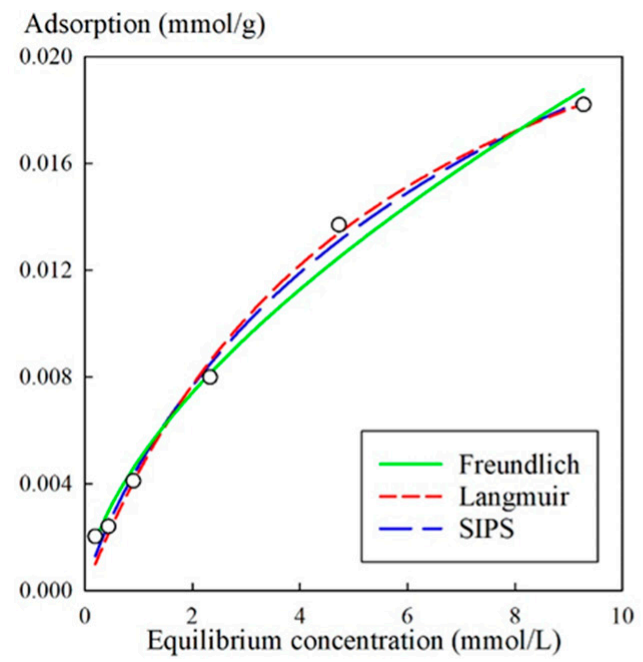

(c)

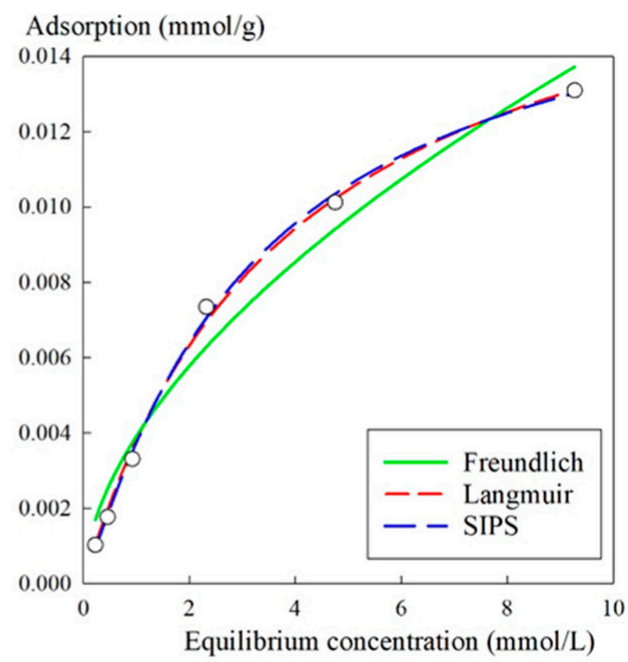

(b)

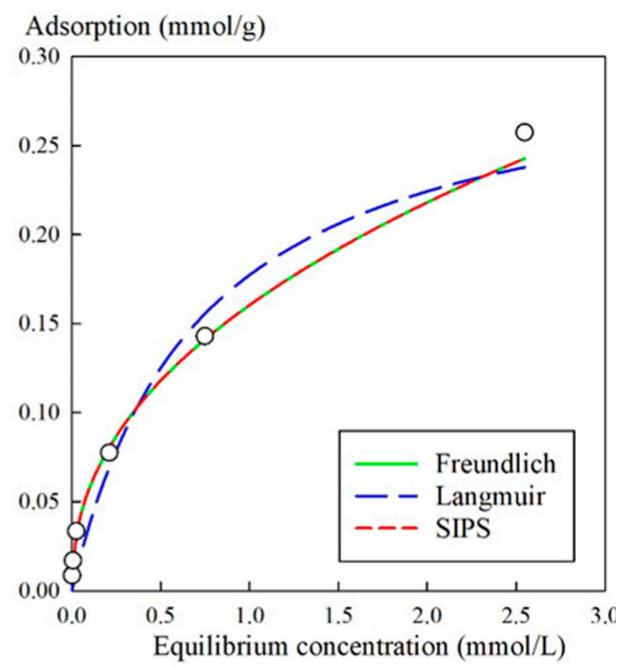

(d)

Figure 5. Isotherms of $\mathrm{Sr}^{2+}$ sorption from $\mathrm{NaCl}$ solution $(0.1 \mathrm{~mol} / \mathrm{L})$ for sorbents: (a) $3 \mathrm{M}$, (b) $3 \mathrm{M}-2$, (c) 3M-4, (d) KU-MAG. Circles represent the experimental data; fit lines were computed using the Freundlich, Langmuir, and Sips equations (Equations (2), (3), and (4), respectively).

Table 3 shows the calculated parameters for experimental values using their respective equations. The KU-MAG sorbent was characterized with the highest values of $G_{m a x}$, as well as $K_{F}$ and $K_{L}$; here, the experimental values could not be adequately described by the Sips equation, in spite of high correlation coefficients. However, it is worth mentioning that high sorption characteristics resulted from adsorption on functional groups of the cation-exchanger rather than on the iron oxide phase. Specific features of the strontium sorption on modified cation-exchangers were discussed in detail in [36]. 
Table 3. Parameters of Freundlich, Langmuir, and Sips equations for the isotherms of $\mathrm{Sr}^{2+}$ sorption on virgin composite sorbents.

\begin{tabular}{|c|c|c|c|c|c|c|c|c|c|c|}
\hline \multirow{2}{*}{ Sorbent } & \multicolumn{2}{|c|}{ Freundlich Equation } & \multicolumn{3}{|c|}{ Langmuir Equation } & \multicolumn{5}{|c|}{ Sips Equation } \\
\hline & $K_{F}$ & $n$ & $R^{2}$ & $K_{L}$ & $G_{\max }$ & $R^{2}$ & $K_{L F}$ & $G_{\max }$ & $n$ & $R^{2}$ \\
\hline $3 \mathbf{M}$ & $\begin{array}{c}0.002 \pm \\
0.0002\end{array}$ & $\begin{array}{c}0.488 \pm \\
0.054\end{array}$ & 0.972 & $\begin{array}{c}0.37 \pm \\
0.05\end{array}$ & $\begin{array}{c}0.009 \pm \\
0.001\end{array}$ & 0.993 & $\begin{array}{c}0.34 \pm \\
0.08\end{array}$ & $\begin{array}{c}0.009 \pm \\
0.002\end{array}$ & $\begin{array}{c}0.92 \pm \\
0.15\end{array}$ & 0.994 \\
\hline $3 M-2$ & $\begin{array}{c}0.004 \pm \\
0.0004\end{array}$ & $\begin{array}{c}0.564 \pm \\
0.064\end{array}$ & 0.973 & $\begin{array}{c}0.26 \pm \\
0.02\end{array}$ & $\begin{array}{c}0.019 \pm \\
0.001\end{array}$ & 0.998 & $\begin{array}{c}0.017 \pm \\
0.001\end{array}$ & $\begin{array}{c}0.28 \pm \\
0.03\end{array}$ & $\begin{array}{c}1.1 \pm \\
0.1\end{array}$ & 0.998 \\
\hline $3 M-4$ & $\begin{array}{c}0.005 \pm \\
0.001\end{array}$ & $\begin{array}{c}0.606 \pm \\
0.044\end{array}$ & 0.989 & $\begin{array}{c}0.18 \pm \\
0.03\end{array}$ & $\begin{array}{c}0.029 \pm \\
0.003\end{array}$ & 0.993 & $\begin{array}{c}0.14 \pm \\
0.06\end{array}$ & $\begin{array}{c}0.039 \pm \\
0.016\end{array}$ & $\begin{array}{c}0.85 \pm \\
0.15\end{array}$ & 0.994 \\
\hline KU-MAG & $\begin{array}{c}0.161 \pm \\
0.001\end{array}$ & $\begin{array}{c}0.443 \pm \\
0.007\end{array}$ & 0.999 & $\begin{array}{c}1.39 \pm \\
0.47\end{array}$ & $\begin{array}{c}0.31 \pm \\
0.04\end{array}$ & 0.975 & $\begin{array}{c}0.004 \pm \\
0.075\end{array}$ & $43 \pm 85$ & $\begin{array}{l}0.45 \pm \\
0.0291\end{array}$ & 0.999 \\
\hline
\end{tabular}

Figure 6 shows the Sr-90 distribution coefficients obtained for the investigated sorption materials. Removal of the radionuclide was performed from $\mathrm{NaCl}$ and $\mathrm{NaOH}$ solutions of concentrations of $0.1 \mathrm{~mol} / \mathrm{L}$. In general, the efficiency of the sorbents was determined by the method of their synthesis, as well as by the $\mathrm{pH}$ value of the solution.

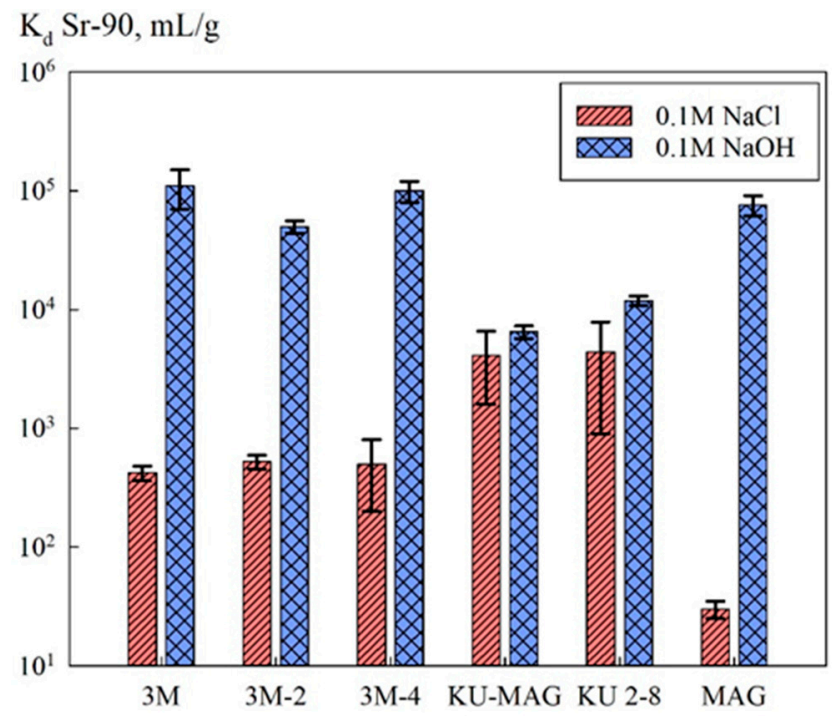

Figure 6. Sorption-selective characteristics of the sorbents.

\section{Discussion}

In the context of the synthesis of magnetic particles of iron oxides in a particular polymer matrix, it was necessary to consider the features of the matrices mentioned above. One of the advantages of the methods for preparing magnetic composites involving chitosan was simplicity of the synthesis of iron oxide particles with chitosan by the method of co-precipitation.

Unlike the XRD image of the KU-MAG resin filled with magnetite, for which a broad diffuse peak characteristic of the KU-2-8 polymer is observed in the 2-theta angle range from 10 to 30 degrees KU-2-8 (Figure 3, curve 2), the image of chitosan filled with iron oxide does not contain peaks inherent to chitosan itself that indicates biopolymer amorphization. The latter simplifies the analysis of iron oxide phases in the composite. The X-ray diffraction analysis data showed that crystalline compounds were formed in the chitosan matrix. Simultaneously with the precipitation of chitosan, phases of $\mathrm{Fe}_{3} \mathrm{O}_{4}$ magnetite and $\mathrm{FeO}(\mathrm{OH})$ goethite were formed. The size and, consequently, the surface area of iron oxides are known to depend on the conditions of crystals formation and growth. The calculated particle sizes are shown in Table 1. Under the conditions of formation in the polysaccharide matrix, the particle size in the magnetic sorbent $3 \mathrm{M}$ equaled $9.7 \mathrm{~nm}$, whereas in the sorbent $3 \mathrm{M}-2$ broadening of 
the peak at $2 \theta 20.9^{\circ}$ on the X-ray pattern indicated a decrease of the particle size (Figure 2, Table 1) down to $5.9 \mathrm{~nm}$.

In the presence of chitosan under hydrothermal conditions at a temperature of $175{ }^{\circ} \mathrm{C}$, magnetite particles of a size of $27.8 \mathrm{~nm}$ were formed; however, the thermal destruction of chitosan occurred at the same time, which excluded the possibility of the production of a composite sorbent. The thermal decomposition of chitosan resulted in a mineral residue in the form of silicon carbide. Since the styrene divinyl-benzene matrix was stable under hydrothermal conditions, it was possible to prepare a composite with particles of a size of $9.7 \mathrm{~nm}$.

According to the provided data (Figure 4), all the studied composite materials were magnetically soft $\left(\mathrm{H}_{\mathrm{c}} \leq 50 \mathrm{e}\right)$, with saturation magnetization values depending on the iron content in the sample. A distinctive feature of the curve of the sample with the lowest iron content consisted of the absence of saturation even under the external field voltage of $10 \mathrm{kOe}$. Such a response of the magnetization dependence curve to the external field of the sample with the lowest iron content indicated that this material contained, in addition to sufficiently large particles with ferromagnetic ordering at room temperature, particles of sizes smaller than the critical one (for $\mathrm{Fe}_{3} \mathrm{O}_{4} \mathrm{~d} \leq 128$ [23]), which manifested superparamagnetic properties.

Figure 6 shows the sorption-selective characteristics of the sorption materials. In general, the efficiency of the radionuclide removal in alkaline media increases substantially, which is related to the formation of strontium complexes [17]. Due to low mineralization, in the case of sorbents KU-MAG and KU 2-8, sorption proceeded mainly on the functional groups of the ion-exchanger [21]. It is worth mentioning that for chitosan-based composites in an alkaline media, while the Sr-90 distribution coefficients remained at the same level along with the decrease of the mass fraction of the inorganic phase. This fact was presumably related to an increase in the accessibility of the sorption sites of magnetite due to the decrease of the particle size. Here, the efficiency of the radionuclide extraction by the chitosan sorbents was comparable to that of the pure magnetite powder.

An interesting feature is concerned with the increase of the values of $G_{\max }$, as well as $K_{L}$ and $K_{L F}$, and the respective decrease of the iron oxide mass fraction at the transition from the $3 \mathrm{M}$ sorbent to $3 \mathrm{M}-4$. The latter corroborates the assumption on the accessibility of sorption sites, likely because of the increase of the surface area of the inorganic phase. Furthermore, the change of the sorbent morphology from the monolith $(3 \mathrm{M})$ to the sponge-like (3M-4) one ensures high accessibility of sorption sites.

\section{Materials and Methods}

Chitosan was purchased from AO Vostok-Bor (Dal'negorsk, Russia); the degree of acetylation was 0.25 , and the viscosity-averaged molecular weight was $250 \mathrm{kDa}$. Iron(III) chloride $\left(\mathrm{FeCl}_{3} \times 6 \mathrm{H}_{2} \mathrm{O}\right)$, iron(II) sulphate $\left(\mathrm{FeSO}_{4} \times 7 \mathrm{H}_{2} \mathrm{O}\right)$, ammonium hydroxide $\left(\mathrm{NH}_{4} \mathrm{OH}\right)$, hydrochloric acid $(\mathrm{HCl})$, strontium (stable) chloride $\left(\mathrm{SrCl}_{2} \times 6 \mathrm{H}_{2} \mathrm{O}\right)$, and sodium hydroxide $(\mathrm{NaOH})$ were purchased from Nevareaktiv (Saint Petersburg, Russia). All chemicals were of the analytical grade and used as received without additional purification.

The synthesis of the composite sorbent based on chitosan (3M) was carried out as follows. A solution containing $0.036 \mathrm{~mol}$ of $\mathrm{Fe}(\mathrm{II})$ and $0.018 \mathrm{~mol}$ of $\mathrm{Fe}(\mathrm{III})$ of a volume of $50 \mathrm{~mL}$ was added to a $1 \%$ chitosan solution of a volume of $300 \mathrm{~mL}$. A solution of $\mathrm{NH}_{4} \mathrm{OH}$ of a concentration of $0.5 \mathrm{~mol} / \mathrm{L}$ was added dropwise to the resulting mixture until a slightly alkaline reaction $(\mathrm{pH} 8)$. The resulting precipitate was filtered under vacuum, washed with distilled water, and dried in air for $48 \mathrm{~h}$. The dried material was additionally heated at $105^{\circ} \mathrm{C}$ for $6 \mathrm{~h}$, after which it was ground, and a fraction of $0.1-0.2 \mathrm{~mm}$ was isolated. The synthesis of the 3M-2 sorbent was performed in a similar way; 50 $\mathrm{mL}$ of a solution containing $0.018 \mathrm{~mol}$ of $\mathrm{Fe}(\mathrm{II})$ and $0.009 \mathrm{~mol}$ of $\mathrm{Fe}(\mathrm{III})$ was added to $300 \mathrm{~mL}$ of a $1 \%$ chitosan solution under constant stirring. The obtained mixture was added dropwise with a $\mathrm{NH}_{4} \mathrm{OH}$ solution of a concentration of $0.5 \mathrm{~mol} / \mathrm{L}$ until a weakly alkaline reaction $(\mathrm{pH} 8)$ occurred. The obtained precipitate was filtered, dried, and ground. 
To synthesize the 3M-4 sorbent, $50 \mathrm{~mL}$ of a solution containing $0.009 \mathrm{~mol}$ of Fe(II) and $0.0045 \mathrm{~mol}$ of $\mathrm{Fe}$ (III) mixed with $300 \mathrm{~mL}$ of a $1 \%$ chitosan solution was used. The obtained mixture was added dropwise with a $\mathrm{NH}_{4} \mathrm{OH}$ solution of a concentration of $0.5 \mathrm{~mol} / \mathrm{L}$ until a weakly alkaline reaction ( $\mathrm{pH}$ ) occurred. The obtained precipitate was filtered, dried, and ground.

Synthesis of the sample marked as MAG was carried out in a similar way as the synthesis of $3 \mathrm{M}$, with the difference being that the precipitate additionally underwent hydrothermal treatment. The wet precipitate was transferred to a Teflon autoclave glass and filled with $50 \mathrm{~mL}$ of $\mathrm{NH}_{4} \mathrm{OH}$ solution of a concentration of $0.1 \mathrm{~mol} / \mathrm{L}$. The hydrothermal treatment was carried out for $24 \mathrm{~h}$ at a temperature of $175^{\circ} \mathrm{C}$, after which the reactor was gradually cooled down to room temperature. The resulting black precipitate was washed with distilled water in a Buchner funnel and dried at $85^{\circ} \mathrm{C}$ until constant weight.

The synthesis of the KU 2-8 resin modified with magnetite (sample KU-MAG) was carried out according to the method suggested in [36]. Wet KU 2-8 resin in the H-form was brought into contact with a solution containing $5 \times 10^{-3} \mathrm{~mol} \mathrm{Fe}(\mathrm{II})$ and $2.5 \times 10^{-3} \mathrm{~mol} \mathrm{Fe}(\mathrm{III})$ for $12 \mathrm{~h}$. Thereafter, the resin was separated from the solution, washed with distilled water, and treated with $\mathrm{NH}_{4} \mathrm{OH}$ solution. Then, the resin was washed from magnetite particles formed outside the resin bulk by means of decantation and transferred to the Teflon autoclave glass. A solution of $\mathrm{NH}_{4} \mathrm{OH}$ with $\mathrm{pH} 11-14$ was added to the resin and autoclaved for $12 \mathrm{~h}$ at a temperature of $175^{\circ} \mathrm{C}$. The resulting resin had a black color.

Markings of the sorbents and their characteristics are provided in Table 4. The KU-Mag sorbent exhibited the lowest content of the mineral phase, which was related to a limited number of sorption sites.

Table 4. Markings and characteristics of the sorbents.

\begin{tabular}{ccc}
\hline Sorbent & Matrix & Content of Inorganic Phase (wt. \%) \\
\hline 3M & Chitosan & 42 \\
3M-2 & Chitosan & 21 \\
3M-4 & Chitosan & 10.5 \\
KU-MAG & Styrene divinyl-benzene & 5.3 \\
KU 2-8 & Styrene divinyl-benzene & - \\
MAG & - & 1000 \\
\hline
\end{tabular}

Prior to the experiments, the model solutions were labeled with the Sr-90 radionuclide (1000 $\mathrm{Bq} / \mathrm{mL}$ ). The removal of strontium was performed under static conditions when the sorbent was continuously stirred with a model solution in a $10 \mathrm{~mL}$ polypropylene cylinder at a rate of 20-30 rpm in a vertical rotary shaker; the stirring proceeded for 7 days. Three parallel samples were used for each experiment, including a test experiment with no sorbent. After the specified time, the model solution was separated from the sorbent by centrifugation at a rate of $4500 \mathrm{rpm}$ for $15 \mathrm{~min}$, after which the residual activity was determined.

The distribution coefficient for Sr was calculated according to the following formula (1):

$$
\mathrm{K}_{d}=\frac{A_{0}-A_{e q}}{A_{e q}} \times \frac{V_{s t}}{m}
$$

where $A_{0}$ is the initial activity of the model solution $(\mathrm{Bq} / \mathrm{mL}), A_{e q}$ is the equilibrium activity of the liquid medium $(\mathrm{Bq} / \mathrm{mL}), V_{s t}$ is the volume of the liquid medium during sorption under static conditions $(\mathrm{mL})$, and $m$ is the mass of the sorbent sample $(\mathrm{g})$.

To describe sorption isotherms, standard equations of Freundlich (3), Langmuir (4), and the combined Langmuir-Freundlich (L-F) Equation (5) were used.

$$
\begin{gathered}
\Gamma=K_{F} \times C^{m} \\
\Gamma=G_{\max } \times \frac{K_{L} \times C}{1+K_{L} \times C}
\end{gathered}
$$




$$
\Gamma=G_{\max } \times \frac{K_{L F} \times C^{m}}{1+K_{L F} \times C^{m}}
$$

where $G_{\max }$ is sorption capacity $(\mathrm{mmol} / \mathrm{g}), C$ is equilibrium concentration of $\mathrm{Sr}(\mathrm{mmol} / \mathrm{L}), K_{F}$ is Freundlich's constant, characterizing the adsorption ability and representing the adsorption value at equilibrium concentration equal to $1 ; K_{L}$ and $K_{L F}$ are constants of adsorption equilibrium characterizing adsorbent-adsorbate binding energy; $m$ is a parameter of sorption site irregularity, characterizing the change of the heat of adsorption depending on the fractional occupancy of the sorption sites.

The activity of the model solutions with respect to $\mathrm{Sr}-90$ was determined using a liquid scintillation alpha-beta radiometer of the spectrometric Tri-Carb 2910 TR device (Perkin Elmer, Norwalk, CT, USA). The X-ray diffraction analysis was performed using a D8 ADVANCE diffractometer (Bruker AXS $\mathrm{GmbH}$, Karlsruhe, Germany); X-ray patterns of the samples were recorded within the angle range $2 \theta$ from $3^{\circ}$ to $85^{\circ}$ with an increment step of $0.02^{\circ}$ at a count of $0.6 \mathrm{~s}$. Identification of the phase composition was performed using the QualX software (version 2.24) and the Crystallography Open Database (27 June 2019). Surface structure images of the investigated materials were obtained by means of scanning electron microscopy on a Carl Zeiss CrossBeam XB 1540 (Oberkochen, Germany) with an attachment for energy dispersive analysis. The results were processed using SciDavis software (version 1.23).

The size $(D)$ of iron oxide particles in the original powder and in composites was determined from the XRD data using the Scherrer Equation (5):

$$
D=\frac{0.94 \lambda}{\beta_{1 / 2} \cos \theta}
$$

where $\beta_{1 / 2}$ is the line broadening in radians, $\theta$ is the Bragg angle, and $\lambda$ is the $\mathrm{X}$-ray wavelength $(\mathrm{CuK}-\alpha$ $1.5406 \AA$ ).

Magnetization of the samples was measured using an MPMS XL-7 SQUID Quantum Design (San Diego, CA, USA) magnetometer in the field range of $\pm 10,000$ Oe at a temperature of $300 \mathrm{~K}$. A measurement step was 100 Oe in the range of 0 to \pm 2000 Oe and to 500 Oe in the range of \pm 2000 to $\pm 10,000$ Oe.

\section{Conclusions}

The creation of composite materials based on several components serves as a platform for the development of advanced technologies for water treatment. Creation of macrosystems with the introduction of nanosized particles, i.e., the development of nanocomposite materials acquiring the advantages of both hosts and immobilized functional particles, represents a promising approach. Hosts (minerals, silicon oxides, activated carbons, polymers, and biopolymers) improve the dispersion and stability of the introduced (loaded) nanoparticles. They can facilitate the transfer or diffusion of the contaminant to the matrix-filling particles (loaded particles). Host matrices most likely prevent the release of guest nanoparticles into the treated solutions. Therefore, it is possible to combine nanocomposites with existing water treatment technologies using nanosystems in boiling bed devices or columns.

In the future, the use of magnetic sorbents will allow the development of more sustainable technologies for water decontamination and the extraction of valuable components from solutions.

Author Contributions: Conceptualization, A.E. and L.Z.; Formal analysis, A.E, I.T., E.T. and N.I.; Investigation, A.M., A.E., E.T., T.S., I.T. and N.I.; Methodology, A.M., I.T. and T.S.; Writing-original draft, A.E. and L.Z.; Writing-review and editing, A.E. and L.Z. All authors have read and agreed to the published version of the manuscript.

Funding: The authors gratefully acknowledged the Ministry of Science of the Russian Federation for supporting this work (State Order No. 0265-2019-0002 of the Institute of Chemistry FEBRAS).

Acknowledgments: Equipment of CUC “Far Eastern Center of Structural Investigations” was used in this work.

Conflicts of Interest: The authors declare no conflict of interest. 


\section{References}

1. Tursi, A.; De Vietro, N.; Beneduci, A.; Milella, A.; Chidichimo, F.; Fracassi, F.; Chidichimo, G. Low pressure plasma functionalized cellulose fiber for the remediation of petroleum hydrocarbons polluted water. J. Hazard. Mater. 2019, 373, 773-782. [CrossRef] [PubMed]

2. Tursi, A.; Chatzisymeon, E.; Chidichimo, F.; Beneduci, A.; Chidichimo, G. Removal of Endocrine Disrupting Chemicals from Water: Adsorption of Bisphenol-A by Biobased Hydrophobic Functionalized Cellulose. Int. J. Environ. Res. Public Health 2018, 15, 2419. [CrossRef]

3. Tursi, A.; Beneduci, A.; Chidichimo, F.; De Vietro, N.; Chidichimo, G. Remediation of hydrocarbons polluted water by hydrophobic functionalized cellulose. Chemosphere 2018, 201, 530-539. [CrossRef] [PubMed]

4. Arias Arias, F.E.; Beneduci, A.; Chidichimo, F.; Furia, E.; Straface, S. Study of the adsorption of mercury (II) on lignocellulosic materials under static and dynamic conditions. Chemosphere 2017, 180, 11-23. [CrossRef] [PubMed]

5. Abdolali, A.; Guo, W.S.; Ngo, H.H.; Chen, S.S.; Nguyen, N.C.; Tung, K.L. Typical lignocellulosic wastes and by-products for biosorption process in water and wastewater treatment: A critical review. Bioresour. Technol. 2014, 160, 57-66. [CrossRef]

6. Joseph, L.; Flora, J.R.V.; Park, Y.-G.; Badawy, M.; Saleh, H.; Yoon, Y. Removal of natural organic matter from potential drinking water sources by combined coagulation and adsorption using carbon nanomaterials. Sep. Purif. Technol. 2012, 95, 64-72. [CrossRef]

7. Guibal, E. Interactions of metal ions with chitosan-based sorbents: A review. Sep. Purif. Technol. 2004, 38, 43-74. [CrossRef]

8. Gerente, C.; Lee, V.K.C.; Cloirec, P.L.; McKay, G. Application of Chitosan for the Removal of Metals from Wastewaters by Adsorption-Mechanisms and Models Review. Crit. Rev. Environ. Sci. Technol. 2007, 37, 41-127. [CrossRef]

9. Bhatnagar, A.; Sillanpää, M. Applications of chitin- and chitosan-derivatives for the detoxification of water and wastewater-A short review. Adv. Colloid Interface Sci. 2009, 152, 26-38. [CrossRef]

10. Varma, A.J.; Deshpande, S.V.; Kennedy, J.F. Metal complexation by chitosan and its derivatives: A review. Carbohydr. Polym. 2004, 55, 77-93. [CrossRef]

11. Crini, G. Recent developments in polysaccharide-based materials used as adsorbents in wastewater treatment. Prog. Polym. Sci. 2005, 30, 38-70. [CrossRef]

12. Liu, B.; Wang, D.; Yu, G.; Meng, X. Adsorption of heavy metal ions, dyes and proteins by chitosan composites and derivatives-A review. J. Ocean Univ. China 2013, 12, 500-508. [CrossRef]

13. Elwakeel, K.Z. Environmental Application of Chitosan Resins for the Treatment of Water and Wastewater: A Review. J. Dispers. Sci. Technol. 2010, 31, 273-288. [CrossRef]

14. Wan Ngah, W.S.; Teong, L.C.; Hanafiah, M.A.K.M. Adsorption of dyes and heavy metal ions by chitosan composites: A review. Carbohydr. Polym. 2011, 83, 1446-1456. [CrossRef]

15. Qu, J. Research progress of novel adsorption processes in water purification: A review. J. Environ. Sci. 2008, 20, 1-13. [CrossRef]

16. Zhang, Y.; Wu, B.; Xu, H.; Liu, H.; Wang, M.; He, Y.; Pan, B. Nanomaterials-enabled water and wastewater treatment. NanoImpact 2016, 3-4, 22-39. [CrossRef]

17. Gómez-Pastora, J.; Bringas, E.; Ortiz, I. Recent progress and future challenges on the use of high performance magnetic nano-adsorbents in environmental applications. Chem. Eng. J. 2014, 256, 187-204. [CrossRef]

18. Wang, J.; Chen, C. Chitosan-based biosorbents: Modification and application for biosorption of heavy metals and radionuclides. Bioresour. Technol. 2014, 160, 129-141. [CrossRef]

19. Tolmacheva, V.V.; Apyari, V.V.; Kochuk, E.V.; Dmitrienko, S.G. Magnetic adsorbents based on iron oxide nanoparticles for the extraction and preconcentration of organic compounds. J. Anal. Chem. 2016, 71, 321-338. [CrossRef]

20. Reddy, D.H.K.; Lee, S.-M. Application of magnetic chitosan composites for the removal of toxic metal and dyes from aqueous solutions. Adv. Colloid Interface Sci. 2013, 201-202, 68-93. [CrossRef]

21. Sarkar, S.; Guibal, E.; Quignard, F.; SenGupta, A.K. Polymer-supported metals and metal oxide nanoparticles: Synthesis, characterization, and applications. J. Nanoparticle Res. 2012, 14, 715. [CrossRef] 
22. Zhang, Q.; Pan, B.; Zhang, W.; Pan, B.; Zhang, Q.; Ren, H. Arsenate Removal from Aqueous Media by Nanosized Hydrated Ferric Oxide (HFO)-Loaded Polymeric Sorbents: Effect of HFO Loadings. Ind. Eng. Chem. Res. 2008, 47, 3957-3962. [CrossRef]

23. Pastukhov, A.V.; Davankov, V.A.; Volkov, V.V.; Amarantov, S.V.; Lubentsova, K.I. Structure and sorption properties of hypercrosslinked polystyrenes and magnetic nanocomposite materials based on them. J. Polym. Res. 2014, 21, 406. [CrossRef]

24. Möller, T.; Sylvester, P. Effect of silica and $\mathrm{pH}$ on arsenic uptake by resin/iron oxide hybrid media. Water Res. 2008, 42, 1760-1766. [CrossRef] [PubMed]

25. Sarkar, S.; Blaney, L.M.; Gupta, A.; Ghosh, D.; SenGupta, A.K. Use of ArsenXnp, a hybrid anion exchanger, for arsenic removal in remote villages in the Indian subcontinent. React. Funct. Polym. 2007, 67, 1599-1611. [CrossRef]

26. Zhang, L.; Zeng, Y.; Cheng, Z. Removal of heavy metal ions using chitosan and modified chitosan: A review. J. Mol. Liq. 2016, 214, 175-191. [CrossRef]

27. Gupta, A.; Chauhan, V.S.; Sankararamakrishnan, N. Preparation and evaluation of iron-chitosan composites for removal of $\mathrm{As}(\mathrm{III})$ and $\mathrm{As}(\mathrm{V})$ from arsenic contaminated real life groundwater. Water Res. 2009, 43, 3862-3870. [CrossRef]

28. Dhoble, R.M.; Lunge, S.; Bhole, A.G.; Rayalu, S. Magnetic binary oxide particles (MBOP): A promising adsorbent for removal of As (III) in water. Water Res. 2011, 45, 4769-4781. [CrossRef]

29. Liu, B.; Wang, D.; Li, H.; Xu, Y.; Zhang, L. As(III) removal from aqueous solution using $\alpha-\mathrm{Fe}_{2} \mathrm{O}_{3}$ impregnated chitosan beads with As(III) as imprinted ions. Desalination 2011, 272, 286-292. [CrossRef]

30. Zemskova, L.; Egorin, A.; Tokar, E.; Ivanov, V.; Bratskaya, S. New Chitosan/Iron Oxide Composites: Fabrication and Application for Removal of $\mathrm{Sr}^{2+}$ Radionuclide from Aqueous Solutions. Biomimetics 2018, 3 , 39. [CrossRef]

31. De Pablo, J.; Rovira, M.; Giménez, J.; Casas, I.; Clarens, F. Magnetite Sorption Capacity for Strontium as a Function of pH. MRS Online Proc. Libr. Arch. 2008, 593, 1107. [CrossRef]

32. Cheng, Z.; Gao, Z.; Ma, W.; Sun, Q.; Wang, B.; Wang, X. Preparation of magnetic Fe3O4 particles modified sawdust as the adsorbent to remove strontium ions. Chem. Eng. J. 2012, 209, 451-457. [CrossRef]

33. Liu, C.-H.; Shih, Y.-J.; Huang, Y.-H.; Huang, C.-P. Kinetic and thermodynamic studies for adsorptive removal of $\mathrm{Sr}^{2+}$ using waste iron oxide. J. Taiwan Inst. Chem. Eng. 2014, 45, 914-920. [CrossRef]

34. Chen, Y.; Wang, J. Removal of radionuclide $\mathrm{Sr}^{2+}$ ions from aqueous solution using synthesized magnetic chitosan beads. Nucl. Eng. Des. 2012, 242, 445-451. [CrossRef]

35. Crystallography Open Database. Available online: https://www.crystallography.net/cod/ (accessed on 26 March 2020).

36. Egorin, A.; Tokar, E.; Kalashnikova, A.; Sokolnitskaya, T.; Tkachenko, I.; Matskevich, A.; Filatov, E.; Zemskova, L. Synthesis and Sorption Properties towards Sr-90 of Composite Sorbents Based on Magnetite and Hematite. Materials 2020, 13, 1189. [CrossRef] [PubMed]

(C) 2020 by the authors. Licensee MDPI, Basel, Switzerland. This article is an open access article distributed under the terms and conditions of the Creative Commons Attribution (CC BY) license (http://creativecommons.org/licenses/by/4.0/). 